\title{
Filantropia corporativa a serviço do capital : uma visão histórico-crítica do fomento da Fundação Ford à produção feminista acadêmica brasileira (1978-1998)
}

\author{
Karolliny Joally das Neves Miranda* \\ Mestranda em História pela Universidade Federal de Campina \\ Grande (UFCG) \\ Michelly Pereira de Sousa Cordão* \\ Professora na Unidade Acadêmica de História da Universidade \\ Federal de Campina Grande (UFCG)
}

\section{Resumo}

No contexto da Guerra Fria (1945-199I), as instituições filantrópicas privadas exerceram um papel determinante no fortalecimento da hegemonia estadunidense. Aqui no Brasil, a instituição que mais atuou nesse sentido foi a Fundação Ford (FF). Entre as inúmeras ações estratégicas empreendidas por esta instituição, destaca-se o apoio financeiro dado por ela à produção feminista acadêmica em nosso país. Dito isso, o presente artigo busca problematizar, através de uma postura histórico-crítica, esse engajamento da FF no avanço da produção feminista acadêmica brasileira, destacando os interesses por trás dessa intervenção. Através da exposição de três exemplos histórico-concretos - sua parceria com a Fundação Carlos Chagas e seu apoio ao jornal Mulherio e à Revista Estudos Feministas - busca-se, também, demonstrar o papel determinante exercido pela FF na institucionalização dos estudos feministas em nosso país. $\mathrm{O}$ artigo tem como base de pesquisa material de cunho bibliográfico, que se trata de uma metodologia já bastante empregada nos processos de construção de conhecimento científico.

Palavras-chave Produção feminista acadêmica brasileira - Fundação Ford - Filantropia corporativa.

Submissão

15/08/2021 Aprovação

26/10/2021 Publicação

$29 /$ II/2O2I

* Contato: karolmirandaoz@gmail.com.

** Contato: michelly.pereira@professor.ufcg.edu.br. 


\title{
Corporate Philanthropy at the Service of Capital: A Historical-Critical View of the Ford Foundation's Promotion of Brazilian Academic Feminist Production (1978-1998)
}

\begin{abstract}
In the context of the Cold War (1945-1991), private philanthropic institutions played a decisive role in strengthening US hegemony. Here in Brazil, the institution that acted the most in this regard was the Ford Foundation (FF). Among the numerous strategic actions undertaken by this institution, the financial support given by it to academic feminist production in our country stands out. That said, this article seeks to problematize, through a historical-critical stance, this engagement of FF in the advancement of Brazilian academic feminist production, highlighting the interests behind this intervention. Through the exhibition of three historical-concrete examples - its partnership with the Carlos Chagas Foundation, and its support for the Mulherio newspaper and the Revista Estudos Feministas - we also seek to demonstrate the decisive role played by FF in the institutionalization of feminist studies in our country. The article is based on bibliographical material research, which is a methodology already widely used in the processes of construction of scientific knowledge.
\end{abstract}

Keywords Brazilian Academic Feminist Production - Ford Foundation - Corporate Philanthropy.

\section{La filantropía empresarial al servicio del capital: una visión histórico-crítica de la promoción de la producción feminista académica brasileña por parte de la Fundación Ford (1978-1998)}

\section{Resumen}

En el contexto de la Guerra Fría (1945-199I), las instituciones filantrópicas privadas jugaron un papel decisivo en el fortalecimiento de la hegemonía estadounidense. Aquí en Brasil, la institución que más actuó en este sentido fue la Fundación Ford (FF). Entre las numerosas acciones estratégicas emprendidas por esta institución, destaca el apoyo financiero que brinda a la producción académica feminista en nuestro país. Dicho esto, este artículo busca problematizar, a través de una postura histórico-crítica, este compromiso de FF en el avance de la producción feminista académica brasileña, destacando los intereses detrás de esta intervención. A través de la exhibición de tres ejemplos histórico-concretos - su alianza con la Fundación Carlos Chagas, y su apoyo al periódico Mulherio y a la Revista Estudos Feministas - también se busca demostrar el papel decisivo que jugó la FF en la institucionalización de los estudios feministas en nuestro pais padres. El artículo se basa en la investigación de material bibliográfico, que es una metodología ya ampliamente utilizada en los procesos de construcción del conocimiento científico.

Palabras clave Producción académica feminista brasileña - Fundación Ford - Filantropía empresarial.

$2 \cdot$ ano XII, n. I7, 202I • ISSN 2179-5487 


\section{Introdução}

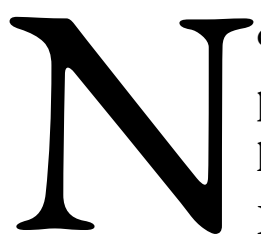

o contexto da Guerra Fria (1945-199I), as instituições filantrópicas privadas exerceram um papel determinante no fortalecimento da hegemonia estadunidense. Instituições como a Fundação Carnegie, Fundação Rockefeller e Fundação Ford, criadas e mantidas por grandes magnatas, ao expandirem a sua atuação para países do Terceiro Mundo, buscavam mantê-los alinhados aos EUA.

Aqui no Brasil, a fundação que mais atuou nesse sentido foi a Fundação Ford (FF). Entre as inúmeras ações estratégicas empreendidas por esta instituição, destaca-se o apoio financeiro dado por ela à produção feminista acadêmica em nosso país. Foi visando promover mudanças na condição social das brasileiras, mudanças estas alinhadas aos parâmetros capitalistas-liberais, que a FF financiou vários grupos e projetos feministas em nossa sociedade civil, bem como destinou volumosos recursos à institucionalização dos estudos feministas na academia brasileira. ${ }^{2}$

De modo geral, ainda são poucos os trabalhos ${ }^{3}$ que, na academia brasileira, têm se preocupado em problematizar a atuação da FF no país. ${ }^{4}$ Por outro lado, muito embora as acadêmicas feministas brasileiras reconheçam o papel determinante exercido pela FF no avanço da nossa produção feminista, elas pouco discutem os interesses que estavam por trás desse apoio fornecido.

Diante disso, e na tentativa de, de algum modo, romper com esse quadro, o presente artigo busca, através de uma postura histórico-crítica, problematizar esse

I CHAVES, W. da S. O Brasil e a recriação da questão racial no pós-guerra: um percurso através da história da Fundação Ford. Tese (Doutorado) - Faculdade de Filosofia, Letras e Ciências Humanas, Universidade de São Paulo, São Paulo, 2oII; ROCHA, E. S. S. A Fundação Ford e o fomento para instituições estratégicas e lideranças acadêmicas no Brasil: análise sobre a parceria com a Fundação Getúlio Vargas. Tese (Doutorado) Instituto de Geociências, Universidade Estadual de Campinas, Campinas, 20I5.

2 SOUZA, M. C. de M. e. "Dos estudos populacionais à saúde reprodutiva". BROOKE, N.; WITOSHNYNSKY, M. (Org.). Os 40 anos da Fundação Ford no Brasil: uma parceria para a mudança Social. Rio de Janeiro: Fundação Ford; São Paulo: Edusp, 2002.

3 Dentre os que foram produzidos, cito: $O$ Brasil e a recriação da questão racial no pós-guerra: um percurso através da história da Fundação Ford (2011), de Wanderson Chaves, e A Fundação Ford e o fomento para instituições estratégicas e lideranças acadêmicas no Brasil: análise sobre a parceria com a Fundação Getúlio Vargas (2015), de Ednéia Rocha. Os dois trabalhos foram de grande relevância para a escrita deste artigo. Tratase de duas pesquisas críticas, produzidas por pesquisadores que não possuem vínculo institucional com a $\mathrm{FF}$ e que não receberam financiamento desta. Nesse sentido, trata-se de trabalhos que se opõem, portanto, às obras redigidas e organizadas por Sérgio Miceli. Este sociólogo é, sim, uma referência obrigatória quando se trata da relação entre a FF e as ciências sociais no Brasil, contudo, as colocações de Chaves nos permitem afirmar que o seu vínculo com a instituição o fez escrever em favor dela.

4 ROCHA, E. S. S. A Fundação Ford e o fomento para instituições estratégicas e lideranças acadêmicas no Brasil: análise sobre a parceria com a Fundação Getúlio Vargas. Tese (Doutorado) - Instituto de Geociências, Universidade Estadual de Campinas, Campinas, 20I5. 


\section{REVISTA ANGELUS NOVUS}

engajamento da FF no avanço da produção feminista acadêmica brasileira, destacando os interesses por trás dessa atuação. Ao tratar desses interesses, não queremos desprezar as ações empreendidas pela FF e os resultados alcançados por elas. Buscamos, isto sim, evitar qualquer tipo de simplismo ingênuo no tratamento dessa questão. Em outras palavras, evitaremos reduzir a atuação da FF a mero imperialismo, ou, de modo oposto, a tratá-la como mera questão de benevolência e caridade - o que não significa dizer que tenhamos uma visão “imparcial” sobre a questão.

Por fim, o artigo ora apresentado tem como base de pesquisa material de cunho bibliográfico, que se trata de uma metodologia já bastante empregada nos processos de construção de conhecimento científico.5 A discussão se estrutura em três partes. $\mathrm{Na}$ primeira, "Filantropia corporativa no contexto da Guerra Fria: aspectos gerais da atuação da Fundação Ford no Brasil”, discutimos as principais ações e estratégias desenvolvidas pela FF aqui no Brasil, mobilizadas no contexto da Guerra Fria. Na segunda, "As mulheres sob a mira da Fundação Ford: a quem interessava a promoção social feminina?”, expomos os principais interesses que levaram a instituição a intervir, a partir do final dos anos 1970, no debate feminista em nossa sociedade. Na terceira e última parte, "O papel da Fundação Ford no avanço da produção feminista acadêmica brasileira: sua parceria com a Fundação Carlos Chagas, e seus apoios ao jornal Mulherio (1981-1987) e à Revista Estudos Feministas (1992-1998)", buscamos demonstrar a importância da FF no avanço do debate feminista acadêmico brasileiro através do resgate: I) de sua parceria com a Fundação Carlos Chagas (FCC), que data de fins dos anos 1970, e de seus financiamentos; 2) ao Mulherio, nos anos 1980, e 3) à Revista Estudos Feministas (REF), nos anos 1990.

\section{Filantropia corporativa no contexto da Guerra Fria: aspectos gerais da atuação da Fundação Ford no Brasil}

A FF foi criada em 1936 por Edsel Ford, filho de Henry Ford, este que foi o fundador da Ford Motor Company, em 19I4, e o idealizador do fordismo. ${ }^{6}$ A criação da instituição foi, na verdade, um esforço da família Ford para driblar a receita federal estadunidense. Assim, os volumosos lucros obtidos pela empresa, ao invés de caírem na malha fina do Estado, iam parar nos fundos da Fundação, que eram empregados na

5 LAKATOS, E. M.; MARCONI, M. de A. Fundamentos de metodologia científica. São Paulo: Atlas, 2003.

6 Modelo de produção que exerceu, ao longo do século XX, grande influência na indústria, sobretudo na norteamericana. Tem como principais características a produção padronizada em massa e em linha de montagem (esteira rolante), técnica que reduz o tempo de produção e estabelece uma divisão rígida de tarefas no interior do processo produtivo.

$4 \cdot$ ano XII, n. I7, 202I • ISSN 2179-5487 
realização de ações filantrópicas a fim de favorecer a imagem pública da empresa frente à sociedade civil estadunidense. ${ }^{7}$

Durante os primeiros quinze anos de existência, a FF realizava ações filantrópicas bastante modestas, que se restringiam a algumas localidades dos EUA. Na década de 1950, contudo, frente ao cenário bipolarizado criado pela Guerra Fria, ela passou a desempenhar uma função social bem mais ampla e complexa, extrapolando os limites do território dos EUA. Nesse momento, a Fundação, a exemplo de outras, passou a atuar em parceria com o Departamento de Estado dos EUA. A aliança, que objetivava a defesa de interesses estadunidenses, previa a extensão das ações dessas instituições privadas para países periféricos, de modo que elas favorecessem a hegemonia do capitalismo nessas regiões. ${ }^{8}$

Foi nesse momento que a FF passou por um processo de internacionalização, a partir da instalação de escritórios em países estratégicos da África, Ásia e América Latina. Se antes a Fundação realizava ações filantrópicas modestas, apenas para manter a sua imagem de "instituição beneficente", agora, nessa nova fase, ela buscava, cada vez mais, firmar-se no ramo da filantropia corporativa, planejando e executando, para tanto, ações minuciosamente calculadas, baseadas em rigorosos critérios de eficiência. ${ }^{9}$

A instalação do escritório da FF no Brasil, na cidade do Rio de Janeiro, em 1962, ocorreu nessa sua nova fase de internacionalização e três anos após a Revolução Cubana (1959). Este evento revolucionário, encabeçado pelos irmãos Castro, e que representou uma contestação ao imperialismo norte-americano, deixou os EUA sob alerta. A partir daquele momento, o Brasil, país da América Latina com o maior índice populacional e com a maior área territorial da região, tornou-se uma área estratégica aos olhos do Estado estadunidense. ${ }^{\text {IO }}$

Desde o início, a atuação da FF no Brasil, à maneira daquelas que ocorriam em outros países subdesenvolvidos, atendia a objetivos bem definidos. O principal deles era o de promover o desenvolvimento socioeconômico do país. Naquele momento, a FF, junto ao departamento de política externa dos EUA, julgava que, uma vez que países subdesenvolvidos, a exemplo do Brasil, passassem a desfrutar das "benesses" trazidas

7 CHAVES, W. da S. O Brasil e a recriação da questão racial no pós-guerra: um percurso através da história da Fundação Ford. Tese (Doutorado) - Faculdade de Filosofia, Letras e Ciências Humanas, Universidade de São Paulo, São Paulo, 20II; ROCHA, E. S. S. A Fundação Ford e o fomento para instituições estratégicas e lideranças acadêmicas no Brasil: análise sobre a parceria com a Fundação Getúlio Vargas. Tese (Doutorado) Instituto de Geociências, Universidade Estadual de Campinas, Campinas, 20I5.

8 CHAVES, W. da S., op. cit.; ROCHA, E. S. S., op. cit.

9 CHAVES, W. da S., op. cit.; ROCHA, E. S. S., op. cit.

Io CHAVES, W. da S., op. cit.; ROCHA, E. S. S., op. cit.

DOI Io.II6o6/issn.2179-5487.vi2ir7pi8959o • s 


\section{REVISTA ANGELUS NOVUS}

pelo desenvolvimento capitalista, eles se tornariam, cada vez mais, "imunes" ao socialismo."

Importante dizer que a noção de desenvolvimento que a FF buscava fomentar nesses países possuía um viés capitalista-liberal-conservador. Isso porque as ações realizadas por ela não buscavam alterar as estruturas socioeconômicas neles vigentes. $\mathrm{Na}$ verdade, eram medidas que buscavam promover certas "melhorias", sem, contudo, modificar a ordem de dominação e privilégios que regia aquelas sociedades. Ou seja, as ações planejadas e implementadas pela FF visavam, no máximo, empreender uma ou outra reforma e integrar, à ordem capitalista, grupos historicamente excluídos dessas sociedades. Nessa perspectiva, tratava-se de medidas que apenas buscavam amenizar os problemas e as contradições sociais, e não, de fato, solucioná-las. ${ }^{12}$

Em sua atuação, a FF priorizava investimentos no campo da educação. $\mathrm{Na}$ visão de seus dirigentes, a educação tanto possibilitava a formação e a capacitação de mão-deobra qualificada, como também permitiria, enquanto instrumento ideológico, a reforma dos valores sociais, a partir da disseminação dos valores liberais/capitalistas (meritocracia, competitividade, individualismo, sucesso profissional etc.), à medida em que também preservava a ordem de dominação e privilégios sociais. ${ }^{13}$

Dentro do campo da educação, a maior parte dos recursos da FF era destinada ao nível superior. ${ }^{14}$ Neste, a área privilegiada foi a das Ciências Sociais. ${ }^{15} \mathrm{Na}$ visão de seus dirigentes, as Ciências Sociais, por desenvolverem estudos sobre a dinâmica da sociedade brasileira, permitiriam à instituição o melhor aproveitamento e direcionamento de seus recursos no país. Além disso, outra vantagem fornecida pela área era a de que ela, através de suas pesquisas, consistiria numa discreta fonte de dados e informações, as quais seriam diretamente repassadas para o Departamento de Estado dos EUA, permitindo a este, no contexto da Guerra Fria, obter mais controle sobre o Brasil. ${ }^{16}$

CHAVES, W. da S. O Brasil e a recriação da questão racial no pós-guerra: um percurso através da história da Fundação Ford. Tese (Doutorado) - Faculdade de Filosofia, Letras e Ciências Humanas, Universidade de São Paulo, São Paulo, 2oII; ROCHA, E. S. S. A Fundação Ford e o fomento para instituições estratégicas e lideranças acadêmicas no Brasil: análise sobre a parceria com a Fundação Getúlio Vargas. Tese (Doutorado) Instituto de Geociências, Universidade Estadual de Campinas, Campinas, 20I5.

I2 CHAVES, W. da S., op. cit.; ROCHA, E. S. S., op. cit.

I3 CHAVES, W. da S., op. cit.; ROCHA, E. S. S., op. cit.

I4 Algumas universidades brasileiras que receberam financiamento da FF foram: UFMG, UFPE, UnB, UFRJ, UFRGS etc., sem contar nos financiamentos que também foram concedidos à Coordenação de Aperfeiçoamento de Pessoal de Nível Superior (CAPES) e ao Conselho Nacional de Desenvolvimento Científico e Tecnológico (CNPq).

Is No ramo das Ciências Sociais, a FF exerceu papel fundamental na criação e manutenção da Associação Nacional de Pós-Graduação e Pesquisa em Ciências Sociais (ANPOCS).

$6 \bullet$ ano XII, n. I7, 202I • ISSN 2179-5487 
$\mathrm{Na}$ academia brasileira, a FF também investiu volumosos recursos na formação de recursos humanos, ou seja, na formação de lideranças e profissionais altamente qualificados. Para os seus dirigentes, a formação de profissionais dentro dos quadros da Fundação forneceria a ela uma chave de acesso indireto ao Estado, ao governo e à sociedade civil brasileira, espaços que progressivamente seriam ocupados por aqueles profissionais e nos quais eles iriam aplicar toda a formação recebida. ${ }^{17}$ Tratar-se-iam, na verdade, de profissionais altamente capacitados, futuros estadistas, juristas e burocratas, que iriam, na visão estratégica da FF, gerir o processo de modernização da sociedade brasileira, mantendo a ordem social preservada e contornando as possíveis contradições surgidas pelo caminho. ${ }^{18}$

Como se vê, a partir desse breve apanhando da atuação da FF no Brasil, no contexto da Guerra Fria, a filantropia praticada por esta instituição não era nem um pouco ingênua e desinteressada. Ao contrário, a sua atuação no país não se tratava de simples caridade, mas sim de intervenção. A partir dessas explanações iniciais, julgamos que ficará mais fácil de tratarmos, no próximo tópico, dos interesses que estavam por trás do apoio que a Fundação deu, no Brasil, à produção feminista desenvolvida na academia.

\section{As mulheres sob a mira da Fundação Ford: a quem interessava a promoção social feminina?}

Como veremos, a análise da bibliografia existente nos permite afirmar que a promoção social das mulheres interessava à FF por pelo menos dois motivos, que se relacionam entre si.

O primeiro deles está associado ao projeto desenvolvimentista perseguido pela Fundação, projeto este que, conforme já vimos, possuía inspiração capitalista-liberalconservadora. Por tratar-se de um projeto que perseguia melhorias sem, contudo, almejar uma reestruturação social, um dos caminhos trilhados por ele se baseava na

I6 CHAVES, W. da S. O Brasil e a recriação da questão racial no pós-guerra: um percurso através da história da Fundação Ford. Tese (Doutorado) - Faculdade de Filosofia, Letras e Ciências Humanas, Universidade de São Paulo, São Paulo, 2oII; ROCHA, E. S. S. A Fundação Ford e o fomento para instituições estratégicas e lideranças acadêmicas no Brasil: análise sobre a parceria com a Fundação Getúlio Vargas. Tese (Doutorado) Instituto de Geociências, Universidade Estadual de Campinas, Campinas, 20I5.

I7 E aqui não podemos deixar de citar o exemplo mais emblemático do sucesso dessa estratégia: Fernando Henrique Cardoso. O ex-presidente do Brasil (1995-2002) foi, durante muitos anos, pesquisador pelo Centro Brasileiro de Análise e Planejamento (Cebrap), instituição mantida pela FF e que resguardou muitos pesquisadores brasileiros perseguidos pela ditadura civil-militar (1964-1985). 


\section{REVISTA ANGELUS NOVUS}

noção de integração social. Ou seja, ao invés de promover mudanças estruturais na sociedade, mudanças estas consideradas perigosas e radicais, a proposta da FF era a de integrar à ordem social, já estabelecida, grupos sociais historicamente excluídos dela. E aqui o grande empenho da Fundação, no Brasil, foi o de promover a inclusão social de negros e mulheres. ${ }^{19}$

Como é sabido, a partir do pós-guerra os movimentos político-sociais de negros e mulheres tomaram, crescentemente, a cena mundial, e adquiriram, cada vez mais, legitimidade social. O fato foi que toda essa agitação não passou despercebida diante da $\mathrm{FF}$, uma instituição que se firmava, cada vez mais, no cenário internacional, e que se arvorava como defensora dos direitos humanos e de ideais progressistas. ${ }^{20}$

Por outro lado, mas não menos importante, a FF passou a entender que investir na promoção social de negros e mulheres consistia numa forma eficaz de controlar tais movimentos, de modo que eles não "saíssem dos trilhos" - ou seja, não resvalassem em extremismos e radicalismos sociais. ${ }^{21}$ Tal estratégia não era nem um pouco infundada. Afinal, basta lembrarmos que tais movimentos, em sua fase inicial de retomada, ao longo das décadas de 1960 e 1970, possuíam feições consideradas extremamente subversivas. ${ }^{22}$

De acordo com o projeto desenvolvimentista, promover a melhoria da condição social feminina também se tratava de uma forma eficaz de reduzir as taxas de natalidade do Brasil, sendo este o segundo motivo que levou a FF a investir na promoção social das mulheres e no debate feminista. ${ }^{23}$

No pós-guerra, o ideal de desenvolvimento pregado pelos EUA e pelas agências internacionais alinhadas aos seus interesses (Organização das Nações Unidas - ONU, Banco Mundial, Organização Mundial da Saúde - OMS etc.) passou a associar desenvolvimento socioeconômico a taxas de fertilidade reduzidas. Com base nessa nova concepção, quanto menores fossem as taxas de natalidade de um país, maiores seriam os

I9 CHAVES, W. da S. O Brasil e a recriação da questão racial no pós-guerra: um percurso através da bistória da Fundação Ford. Tese (Doutorado) - Faculdade de Filosofia, Letras e Ciências Humanas, Universidade de São Paulo, São Paulo, 2oII; ROCHA, E. S. S. A Fundação Ford e o fomento para instituiçôes estratégicas e lideranças acadêmicas no Brasil: análise sobre a parceria com a Fundação Getúlio Vargas. Tese (Doutorado) Instituto de Geociências, Universidade Estadual de Campinas, Campinas, 20I5.

$20 \quad$ CHAVES, W. da S., op. cit.; ROCHA, E. S. S., op. cit.

2I Naquele momento, seja dito, a FF não foi a única instituição que passou a se engajar na "causa feminista". A Organização das Nações Unidas (ONU), por exemplo, é bastante lembrada pela dianteira que passou a exercer na direção dos movimentos feministas a partir dos anos 1970. Para saber mais, leia: FEDERICI, S. "Rumo a Pequim: como a ONU colonizou o movimento feminista”. O ponto zero da revolução: trabalbo doméstico, reprodução e luta feminista. São Paulo: Elefante, 2019.

22 CHAVES, W. da S., op. cit.; ROCHA, E. S. S., op. cit.

23 SOUZA, M. C. de M. e. "Dos estudos populacionais à saúde reprodutiva". BROOKE, N.; WITOSHNYNSKY, M. (Org.). Os 40 anos da Fundação Ford no Brasil: uma parceria para a mudança Social. Rio de Janeiro: Fundação Ford; São Paulo: Edusp, 2002.

$8 \cdot$ ano XII, n. I7, 202I • ISSN 2I79-5487 
seus índices de desenvolvimento. Nesse sentido, reduzir as taxas de natalidade dos países subdesenvolvidos era fundamental para que eles pudessem alcançar uma melhor condição socioeconômica, de acordo com a visão da Fundação. ${ }^{24}$

Por outro lado, não se pode ignorar que, no contexto da Guerra Fria, essa questão da redução das taxas natalidade dos países subdesenvolvidos também esteve associada, de forma mais velada, aos interesses do Departamento de Estado estadunidense. Naquele momento, este trabalhava com a perspectiva de que altos índices populacionais, associados a problemas como fome e pobreza, eram fermentadores de agitações e revoltas sociais que poderiam, inclusive, desembocar no socialismo. Temendo que isso ocorresse, a recomendação dada pelos EUA às instituições de fomento, suas aliadas, era a de que elas, ao atuarem nas regiões periféricas do mundo, promovessem ações no sentido de reduzir as suas taxas de nascimentos. ${ }^{25}$

No Brasil, ao reconstruir-se a trajetória de atuação da FF, entende-se como esse objetivo, o de reduzir as taxas de natalidade, intimamente se articulou com as ações estratégicas da Fundação, que investiu volumosas quantias na promoção do debate feminista em nossa sociedade.

No que tange especificamente ao projeto de reduzir as taxas de natalidade do Brasil, a análise bibliográfica dos textos consultados nos permite dividir a atuação da Fundação em dois momentos. No primeiro, ocorrido entre as décadas de 1960 e 1970, a FF se empenhou na criação de toda uma infraestrutura que permitisse ao Brasil a redução de suas taxas de nascimentos. Nesse momento, os recursos da Fundação foram destinados, prioritariamente, ao desenvolvimento e aprimoramento de métodos contraceptivos, à formação de pesquisadores e profissionais das áreas de biomedicina, demografia, fisiologia humana, biologia reprodutiva etc., e à instalação, no país, de programas de planejamento familiar. ${ }^{26}$

Datam desse momento, por exemplo, a criação da Sociedade Civil Bem-Estar Familiar no Brasil (BEMFAM). A organização foi criada em 1967, e reunia médicos, ginecologistas e obstetras, e cientistas sociais - o sociólogo Gilberto Freyre, inclusive, chegou a atuar na Sociedade. A atuação dessa organização se estendia por todo o país através de uma rede composta por dezenas de clínicas de planejamento familiar.

24 SOUZA, M. C. de M. e. "Dos estudos populacionais à saúde reprodutiva”. BROOKE, N.; WITOSHNYNSKY, M. (Org.). Os 40 anos da Fundação Ford no Brasil: uma parceria para a mudança Social. Rio de Janeiro: Fundação Ford; São Paulo: Edusp, 2002.

25 PEDRO, M. J. P. “As representações do corpo feminino nas práticas contraceptivas, abortivas e no infanticídio - século XX”. MATOS, M. I. S. de; SOIHET, R. (Org.). O corpo feminino em debate. São Paulo: Editora Unesp, 2003. 


\section{REVISTA ANGELUS NOVUS}

Segundo representantes da própria $\mathrm{FF}^{, 7}$ os investimentos concedidos à BEMFAM foram utilizados na realização de estudos e pesquisas sobre contracepção, bem como na realização de treinamentos e no fornecimento de serviços de planejamento familiar que incluíam a distribuição de pílulas, a aplicação de dispositivos intrauterinos (DIU) e a realização de esterilizações. ${ }^{28}$

Em um segundo momento, contudo, a FF apresenta uma nova estratégia. Após duas décadas de atuação no Brasil, os seus dirigentes passaram a reconhecer que somente a criação de uma infraestrutura material não seria suficiente para que as taxas de natalidade do país diminuíssem de forma substancial. Desse modo, a partir dos anos 1980, a FF passou a incluir em sua agenda o apoio a ações e projetos que visassem o engajamento e a promoção socioeconômica das mulheres. ${ }^{29}$

Com base no exemplo fornecido pelos países desenvolvidos e na noção de que "o desenvolvimento é o melhor contraceptivo", a Fundação passou a encarar que, quanto maiores fossem as oportunidades educativas e profissionais dadas às brasileiras, mais estas optariam por terem menos filhos - ou até mesmo por não os terem. Assim, foi visando o cultivo de uma cultura liberal que valorizasse o empoderamento e independência individual das mulheres, que a Fundação passou a investir, no Brasil, na produção feminista, sobretudo a que se realizava no espaço universitário. ${ }^{30}$

Entre as décadas de 1980 e 1990, setores dos movimentos feministas brasileiros, com destaque para aqueles vinculados à academia, beneficiaram-se exponencialmente dessa nova política da Fundação. No próximo tópico trataremos brevemente sobre esses benefícios ao falarmos um pouco sobre a parceria que a FF firmou com a FCC, e de duas produções feministas financiadas por ela: o Mulherio (1981-1987) e a Revista Estudos Feministas (1992-1998), ambas marcantes na história do feminismo nacional. Como veremos, os recursos fornecidos por essa instituição foram decisivos para a criação dessas produções, bem como lhes permitiram adquirir consistência e relevância social. WITOSHNYNSKY, M. (Org.). Os 40 anos da Fundação Ford no Brasil: uma parceria para a mudança Social. Rio de Janeiro: Fundação Ford; São Paulo: Edusp, 2002.

28 Grupos feministas e membros da sociedade civil brasileira, de modo geral, denunciaram as violações dos direitos reprodutivos cometidas pela BEMFAM entre os anos 1980 e 1990. Tais denúncias, inclusive, levaram à abertura, no ano de 1992, de uma Comissão Parlamentar Mista de Inquérito (CPMI), no Congresso Nacional. Uma das denúncias mais graves era a de que a BEMFAM realizou esterilizações em massa em regiões mais pobres do país, sem o consentimento das mulheres. Para saber mais, veja: BIROLI, F. Gênero e desigualdades: limites da democracia no Brasil. São Paulo: Boitempo, 2018. 
MIRANDA Ė CORDÃO • "Filantropia corporativa a serviço do capital"

\section{O papel da Fundação Ford no avanço da produção feminista acadêmica brasileira: sua parceria com a Fundação Carlos Chagas (1978) e seu apoio ao jornal Mulherio (1981-1987) e à Revista Estudos Feministas (1992-1998)}

No Brasil, uma das primeiras beneficiárias da nova política da FF foi a Fundação Carlos Chagas (FCC), que, no país, tratou-se de "[...] um importante núcleo aglutinador de pesquisadoras e feministas”. ${ }^{31}$

A FCC é uma instituição privada, criada em 1964, na cidade de São Paulo, por um grupo de professores da Universidade de São Paulo (USP). A princípio, com o nome de Centro de Seleção de Candidatos a Escolas Médicas e Biológicas (CESCEM), sua função era a de fazer seleções de vestibulandos da área da saúde. Em I971, mudou o seu nome para Fundação Carlos Chagas e passou a financiar pesquisas voltadas para as áreas da educação, do trabalho e da condição da mulher e do negro no Brasil.

Segundo os relatos disponíveis, ${ }^{32}$ em 1974 a FCC fundou o Coletivo de Pesquisas sobre a Mulher (CPM), que foi substituído, no ano seguinte, 1975, pelo Programa de Pesquisas sobre o Trabalho e a Educação da Mulher (PPTEM). A partir dessas iniciativas, a FCC sinalizava o seu interesse em estimular o desenvolvimento da área no Brasil, através do apoio a pesquisas individuais, da realização de levantamentos bibliográficos e de concursos de pesquisas, e da criação de um centro de documentação sobre a condição da "mulher brasileira".

Conforme esses mesmos relatos, a parceria entre a FCC e a FF com vistas a promover os estudos da mulher no Brasil data de 1978, quando da realização do primeiro Concurso de Dotações para Pesquisa sobre a Mulher Brasileira, sob a coordenação da pesquisadora Carmen Barroso.

$\mathrm{Na}$ década seguinte, 1980 , a FCC já figurava como uma das principais donatárias da FF no Brasil. ${ }^{33}$ Naquele momento, conforme Heilborn e Sorj, ${ }^{34}$ a FCC era a instituição que fornecia, na visão da $\mathrm{FF}$, as melhores condições para o aproveitamento de seus

3I CORRÊA, M. "Do feminismo aos estudos de gênero no Brasil: um exemplo pessoal”. Cadernos Pagu, v. i6, n. I, p. I3-30, 200I. p. I8.

32 SOUZA, M. C. de M. e. "Dos estudos populacionais à saúde reprodutiva". BROOKE, N.; WITOSHNYNSKY, M. (Org.). Os 40 anos da Fundação Ford no Brasil: uma parceria para a mudança Social. Rio de Janeiro: Fundação Ford; São Paulo: Edusp, 2002.

33 Segundo artigo de 2002, no período de 1982 a 1997, a FCC recebeu, da FF, pouco mais que 9oo mil dólares (ADORNO, S.; CARDIA, N. "Das análises sociais aos direitos humanos". BROOKE, N.; WITOSHNYNSKY, M. (Org.). Os 40 anos da Fundação Ford no Brasil: uma parceria para a mudança social. Rio de Janeiro: Fundação Ford; São Paulo: Edusp, 2002).

34 HEILBORN, M. L.; SORJ, B. "Estudos de gênero no Brasil (1975-1995)". MICELLI, S. (Org.). O que ler na ciência social brasileira (I970-1995). São Paulo: Sumaré, 1999. 


\section{REVISTA ANGELUS NOVUS}

recursos. Isso porque, além do fato de que ela já dispunha, na época, de uma estrutura organizacional, ela também já havia iniciado, conforme dito, investidas na área dos estudos feministas.

O acervo bibliográfico por ora consultado nos permite afirmar que essa parceria institucional contribuiu para a emergência de uma nova fase no âmbito da produção feminista acadêmica nacional. Se durante a maior parte dos anos 1970 os estudos feministas buscavam se firmar na academia brasileira, lançando esforços sobretudo para provar a sua relevância científico-social, no final da década eles passavam a experimentar um crescente processo de institucionalização para o qual o empenho da FCC, custeado em grande medida pela FF, foi determinante.

Os frutos dessa mudança foram muitos, tanto em termos quantitativos como em termos qualitativos. Segundo Rosemberg, ao longo da década de 1970, os poucos estudos sobre a mulher produzidos no Brasil se limitavam à figura da "mulher trabalhadora". Além disso, o teor militante desses trabalhos acabava, na maioria dos casos, por empobrecer as suas bases teórico-metodológicas, que eram, naquele momento, majoritariamente marxistas. A partir de fins dos anos 1970, contudo, diante da crescente institucionalização, esse quadro passava a se transformar consideravelmente. As pesquisas, cada vez mais numerosas, passavam a abrigar uma crescente diversidade temática (família, sexualidade, reprodução etc.) e teóricometodológica (com abordagens provenientes da antropologia e da psicologia, por exemplo).35

A partir de $\operatorname{Costa}^{36}$ também podemos alegar que a influência da institucionalização no aumento do número desses trabalhos também não pode passar despercebida. Até o início da década de 1970, as pesquisas chegam a revelar que o Brasil contava com apenas quatro trabalhos com foco na condição feminina. Entre 1975 e 1984, período em que os estudos feministas passaram a desfrutar de maior legitimidade, esse número saltou para nada menos que 140 produções, entre dissertações e teses defendidas.

Foi em meio a esse cenário bastante promissor que foi criado, com apoio das fundações FF e FCC, o Mulherio, jornal feminista brasileiro produzido na década de 1980. Na história da imprensa feminista brasileira, ele se destaca por ter sido o jornal com o maior tempo de duração, que abrange quase uma década de publicações: de I98I a 1988. Nesse ponto, o papel da FF também foi fundamental, visto que foi o apoio

35 ROSEMBERG, F. "Estudos sobre a mulher e relações de gênero". MICELI, S. (Org.). A Fundação Ford no Brasil. São Paulo: Sumaré, 1993.

36 COSTA, A. et al. "Pesquisa sobre a mulher no Brasil: do limbo ao gueto?". Cadernos de Pesquisa, v. 54, p. 5-15, I985.

I2 $・$ ano XII, n. I7, 2021 ・ ISSN 2179-5487 
financeiro fornecido por ela o que garantiu a manutenção do Mulherio ao longo de todos esses anos. ${ }^{37}$

Tal fato não pode ser menosprezado. De modo geral, a imprensa feminista brasileira é composta por produções que tiveram uma vida muito curta e incerta, justamente em função da falta de financiamentos. Nos anos 1970, por exemplo, a falta de recursos havia sido fatal para o Nós Mulheres (1976-1978) e o Brasil Mulher (19751980), estes que são considerados os primeiros periódicos feministas brasileiros..$^{38}$

Por outro lado, podemos afirmar, a partir de Teles e Leite, ${ }^{39}$ que o fato de dispor de recursos financeiros também permitiu ao Mulberio, em comparação com aqueles primeiros jornais, dispor de uma feição mais profissional, e não meramente panfletária, característica esta que prevalecia naquelas primeiras produções.

Nos anos 1980, momento em que o Mulherio foi produzido, o feminismo brasileiro também vivia uma nova fase. Após o rompimento com os grupos de esquerda, as organizações feministas passaram a desfrutar de mais autonomia. ${ }^{40} \mathrm{Um}$ reflexo direto dessas mudanças se encontra no próprio Mulherio. Este, diferentemente dos primeiros jornais feministas, produzidos na década de 1970, dava muito mais ênfase às pautas "específicas" das mulheres. ${ }^{41}$

Importantes nomes da história do feminismo brasileiro integraram o corpo editorial do Mulherio: Carmen Barroso, Carmen da Silva, Elisabeth S. Lobo, Eva Blay, Fúlvia Rosemberg, Heleieth Saffioti, Lélia Gonzalez, Marisa Corrêa etc. A maioria das feministas que passou pelo jornal possuía vínculo profissional com FCC, na qual desenvolviam pesquisas sobre a condição feminina brasileira. Ao ser criado, o principal objetivo do Mulherio era o de justamente divulgar as questões levantadas por essas pesquisas para um público mais amplo, de modo que elas não se limitassem ao espaço acadêmico. ${ }^{42}$

\footnotetext{
37 Segundo Adorno e Cardia, representantes oficiais da FF, no período de 1984 a 1987, o Mulberio recebeu, da FF, quase zIo mil dólares (ADORNO, S.; CARDIA, N. "Das análises sociais aos direitos humanos". BROOKE, N.; WITOSHNYNSKY, M. (Org.). Os 40 anos da Fundação Ford no Brasil: uma parceria para a mudança social. Rio de Janeiro: Fundação Ford; São Paulo: Edusp, 2002).

38 TELES, A; LEITE, R. S. C. Da guerrilha à imprensa feminista: a construção do feminismo pós-luta armada no Brasil (1975-1980). São Paulo: Intermeios, 2013.

39 Ibidem.

40 Dizer que determinados setores feministas romperam com os grupos de esquerda não é o mesmo que dizer que elas renegaram, de todo, a tradição marxista. Significa, apenas, que elas tomaram outros rumos em termos organizacionais.

TAMIÃO, J. S. Escritas feministas: os jornais Brasil Mulher, Nós Mulheres $e$ Mulherio (1975-1988). Dissertação (Mestrado) - Pontifícia Universidade Católica de São Paulo, São Paulo, 2009.

42 Mulherio, março/abril, $198 \mathrm{I}$.
} 


\section{REVISTA ANGELUS NOVUS}

O Mulherio recebeu financiamento da FCC até 1983 e da FF até 1987. Após perder este apoio, ele passou a se chamar Nexo, Feminismo, Informação e Cultura. Além da alteração do nome, o seu foco, que antes recaía sobre pautas feministas, passou a ser mais cultural, visando assim atrair um público mais amplo para se manter em circulação. Todavia, essas mudanças não surtiram efeito. A falta de financiamento foi fatal para essa produção que, em julho de 1988, encerrou as suas atividades.

Destino bem diferente é aquele partilhado pela Revista Estudos Feministas (REF), um projeto que, assim como o Mulberio, recebeu apoio da FF, mas que, ao contrário dele, não somente permanece em atividade, mas também se tornou, na opinião de muitos pesquisadores da área, o melhor periódico acadêmico da América Latina sobre estudos feministas e de gênero da atualidade. ${ }^{43}$

A REF foi criada em 1992, durante o encontro anual da Associação Nacional de Pós-Graduação e Pesquisa em Ciências Sociais (ANPOCS). O apoio fornecido pela FF à $\mathrm{REF}$, em seu início, integrava as políticas da instituição a fim de fortalecer os estudos feministas na academia brasileira. Nesse sentido, a criação da REF, nos anos 1990, registra não apenas o sucesso dessas políticas, implementadas, conforme vimos, desde fins dos anos 1970, mas também o desejo de avançar na sofisticação dessa área. ${ }^{44}$

Ao ser criada, um dos objetivos da Revista era o de que ela se tornasse: "[...] um instrumento educativo e político de difusão das pesquisas acadêmicas em gênero e feminismo, com a pretensão de ser também um veículo de formação para os movimentos de mulheres". ${ }^{45}$ Além disso, outra ambição traçada pelos editores da REF, junto aos seus financiadores, era a de que ela se constituísse numa publicação acadêmica de alto nível, regida por rigorosos critérios científicos.

Entre 1992 e 1998, a REF recebeu financiamento direto da FF. Durante esse período, ela era editada no Rio de Janeiro. Ao longo desses anos, importantes nomes passaram por ela: Heleieth Saffioti, Heloísa Buarque de Hollanda, Mary Garcia Castro etc. Além disso, importantes temas foram discutidos em suas páginas: a situação das empregadas domésticas, as vivências de mulheres indígenas, negras e idosas, as relações entre feminismos e educação, literatura, meio ambiente etc. ${ }^{46}$

Nas palavras de Grossi, o financiamento fornecido pela FF à REF funcionou, em certo sentido, como uma "faca de dois gumes". Isso porque ele foi, sim, determinante

43 DINIZ, D.; FOLTRAN, P. "Gênero e feminismo no Brasil: uma análise da Revista Estudos Feministas". Estudos Feministas, v. 12, n. spe., p. 245-253, 2004.

44 Ibidem.

45 Ibidem.

46 GROSSI, M. “A Revista Estudos Feministas faz Io anos: uma breve história do feminismo no Brasil”. Estudos Feministas, v. I2, n. spe., p. 2II-22I.

I4 $\bullet$ ano XII, n. I7, 202I • ISSN 2179-5487 
para a criação e manutenção da Revista nesses primeiros anos, entretanto, ele também alimentou uma certa situação de dependência por parte da produção. Assim, após a instituição anunciar o fim do apoio, em 1998, a Revista teve que realizar uma série de reestruturações para se manter em atividade. Dentre as mudanças, a sede da REF foi transferida para Florianópolis, em 1999, e ela passou a ser editada pela Universidade Federal de Santa Catarina (UFSC), situação que se mantém até os dias atuais. ${ }^{47}$

De modo geral, pode-se dizer que essas intervenções da FF contribuíram para o aprofundamento de problemas característicos do feminismo brasileiro. De fato, e é importante deixar isto explícito, não se trata de problemas criados pela própria FF. Trata-se, na verdade, de limitações que, de algum modo, já faziam parte da dinâmica histórico-social do feminismo brasileiro e a atuação da FF apenas contribuiu para reforçá-las.

Começamos destacando que a presença da FF contribuiu para acentuar, no feminismo brasileiro, o seu traço mais acadêmico. Nesse sentido, as grandes cifras investidas pela FF na produção acadêmica brasileira, em meio ao cenário de censura e repressão vigente durante a ditadura, foram fatores que contribuíram para que a reflexão feminista praticada no Brasil tivesse como lócus primordial o ambiente institucional das universidades e dos centros de pesquisa. ${ }^{4}$

Por desenvolver-se nesse ambiente mais formal, e nas sombras da ditadura, o feminismo brasileiro também acabou partilhando deste traço bem mais moderado e reformista, o que é ainda mais realçado quando comparado aos feminismos de outros países - estes, não custa nada frisar, partilham de trajetórias distintas. À diferença do que ocorreu nos EUA, por exemplo, onde as feministas empreenderam um ataque bem mais incisivo ao establishment científico, as feministas acadêmicas brasileiras procuraram se inserir nas estruturas acadêmicas já instauradas. Em outras palavras, enquanto nos EUA as feministas-pesquisadoras buscaram reestruturar a instituição universitária e os parâmetros científicos que regiam a produção de conhecimento, aqui no Brasil as pesquisadoras-feministas limitaram seus esforços à conquista de um "lugar ao sol” na academia. ${ }^{49} \mathrm{E}$ aqui não se trata de julgar qual dessas duas posturas foi a "mais" feminista, mas sim de tentar entender que eram propostas distintas, tomadas em contextos histórico-concretos também distintos.

48 HEILBORN, M. L.; SORJ, B. "Estudos de gênero no Brasil (1975-1995)". MICELLI, S. (Org.). O que ler na ciência social brasileira (1970-1995). São Paulo: Sumaré, 1999. 


\section{REVISTA ANGELUS NOVUS}

Além de priorizarem a academia, outra crítica recorrente é a de que as pesquisadoras-feministas brasileiras adotaram uma postura um tanto isolacionista, por assim dizer. Isso porque elas se mantiveram numa distância muito grande dos movimentos de mulheres, alargando, assim, o abismo entre teorias e práticas, pesquisa $\mathrm{e}$ militância, tão caraterístico da sociedade brasileira. ${ }^{50}$

No âmbito da produção feminista, outro abismo reforçado pela intervenção da FF, também estrutural na academia brasileira, é aquele que opõe pesquisa versus ensino. Aqui, os esforços da FF tenderam a supervalorizar a pós-graduação, na medida em que a educação básica ou até mesmo a própria graduação eram pouco consideradas. Assim, era muitas vezes em cursos de mestrado e doutorado que estudiosos tinham acesso àquilo que estava sendo produzido no âmbito dos estudos feministas..$^{5 \mathrm{I}}$

Rosemberg, pesquisadora feminista brasileira que, durante anos, esteve vinculada à FCC e chegou a integrar o Mulberio, também destaca que a escolha da FF por financiar pequenos projetos de pesquisa individuais contribuiu para a fragmentação dos estudos feministas brasileiros e desestimulou a realização de trabalhos em equipe. ${ }^{52}$

Além disso, em diálogo com as desigualdades e privilégios sociais vigentes no Brasil, é valido relembrarmos que as pesquisadoras que obtinham financiamento por essas instituições eram, em sua maioria, mulheres brancas e pertencentes à classe média dos grandes centros urbanos do país. Sobre este último ponto, destaco que por mais que a FF tenha lançado alguns esforços para integrar as regiões Norte e Nordeste à produção feminista brasileira, ${ }^{53}$ seus investimentos privilegiavam, de forma bastante desproporcional, os grandes centros de pesquisa do Sul e do Sudeste. Nesse ponto, a atuação da FF também reforçou a desigualdade regional que também se reflete no âmbito da produção científica no Brasil. ${ }^{54}$

\section{Considerações finais}

Ao longo desse texto, buscamos entender os interesses que levaram a Fundação Ford a investir pesadas cifras na produção feminista acadêmica em nosso país.

so CORRÊA, M. "Do feminismo aos estudos de gênero no Brasil: um exemplo pessoal”. Cadernos Pagu, v. i6, n. I, p. 13-30, 200I.

5I ROSEMBERG, F. "Estudos sobre a mulher e relações de gênero". MICELI, S. (Org.). A Fundação Ford no Brasil. São Paulo: Sumaré, 1993.

52 Ibidem.

53 O principal deles foi a criação, em 1992, da Rede Regional do Norte-Nordeste de Estudos e Pesquisas sobre a Mulher e Relações de Gênero (REDOR).

54 ROSEMBERG, F., op. cit.

I6 $\bullet$ ano XII, n. 17, 202I • ISSN 2179-5487 
Conforme foi discutido, a análise bibliográfica nos permite dizer que tal intervenção obedecia a dois objetivos estratégicos desta instituição que remontam ao contexto da Guerra Fria: I) o de avançar no desenvolvimento capitalista do Brasil, desenvolvimento este de viés liberal-conservador e que buscava, entre outras coisas, a inclusão social das mulheres, e 2) o de reduzir as taxas de natalidade do país. Este último se articulava ao projeto desenvolvimentista, mas também aos interesses mais imediatos do Departamento de Estado estadunidense, que enxergava nas altas taxas de nascimentos um terreno fértil para o socialismo.

Demonstramos também, a partir de exemplos histórico-concretos, como setores do feminismo brasileiro, sobretudo aqueles vinculados ao ambiente acadêmico, beneficiaram-se dos investimentos da FF. Através dos casos abordados (FCC, Mulberio e REF), vimos como tais investimentos foram cruciais para o crescimento, diversificação, sofisticação e divulgação da produção feminista acadêmica brasileira. Contudo, apesar desses ganhos, vimos que tal intervenção igualmente contribuiu para o aprofundamento de problemas estruturais que caracterizam o movimento feminista em nosso país.

Aqui também julgamos importante, mais uma vez, criticar posições simplistas, que alegam que a FF apenas instrumentalizou o nosso feminismo. Como enfatizamos nesta pesquisa, a FF, ao investir na promoção do debate feminista, possuía, sim, os seus interesses e, nessa relação de poder, é inegável o fato de que ela exercia mais influência. Contudo, arriscamo-nos a dizer que a relação estabelecida por ela com setores do movimento feminista brasileiro deve ser encarada como uma via de mão dupla, na qual as feministas também buscavam as suas vantagens. A própria FF reconhece, em seus relatos, que a parceria com as feministas nem sempre ocorria livre de tensões. 55

Por fim, o que pretendemos fazer ao longo desse artigo, e esperamos ter alcançado êxito, foi lançar questões, a partir da bibliografia já existente, para darmos início a esse debate. Dado esse passo inicial, a pretensão é de, no futuro, aprofundarmos essa discussão, sobretudo em termos analíticos: partindo para a análise de fontes, exploração de conceitos etc. Por ora, estamos satisfeitas com a discussão até aqui apresentada, pois, como sabemos, os objetos de estudo não estão prontos, em algum lugar, ocultos, esperando serem descobertos (“eureca!”), mas são construídos (ampliados, aprimorados, superados), continuamente, pelos pesquisadores. 